\title{
TITLE:
}

\section{MORPHOLOGICAL DIFFERENCES OBSERVED BETWEEN THE GENERATIONS OF THE SAME CHAETOGNATH POPULATION}

\author{
$\operatorname{AUTHOR}(\mathrm{S})$ : \\ Tokioka, Takasi
}

\section{CITATION:}

Tokioka, Takasi. MORPHOLOGICAL DIFFERENCES OBSERVED BETWEEN THE

GENERATIONS OF THE SAME CHAETOGNATH POPULATION. PUBLICATIONS OF THE SETO MARINE BIOLOGICAL LABORATORY 1974, 21(3-4): 269-279

ISSUE DATE:

1974-03-30

URL:

http://hdl.handle.net/2433/175864

RIGHT: 


\title{
MORPHOLOGIGAL DIFFERENGES OBSERVED BETWEEN THE GENERATIONS OF THE SAME CHAETOGNATH POPULATION ${ }^{13}$
}

\author{
TAKASI TOKIOKA
}

Seto Marine Biological Laboratory

With Text-figures 1-4

Aidanosagitta crassa forma naikaiensis (Tokioka) was defined as a form of Sagitta crassa Tokioka in spite of the existence of very clear differences between these two in the body size of mature individuals and the appearance or the degree of development of the collarette, because a few specimens showing some intermediate states were found together with f. naikaiensis (Tokioka, 1939 a). Later, it was supposed that f. naikaiensis might be a form inhabiting smaller and somewhat protected sea areas with higher temperature (and possibly salinity, too), while the typical form might be limited to the waters rather open and with relatively lower temperature (and probably salinity, too), but without any actual evidences being presented about this.

Kado (1954) and Murakami (1959) made comprehensive studies of f. naikaiensis and the typical form occurring in the Inland Sea of Japan and both authors reached the conclusion that $\mathrm{f}$. naikaiensis is a form in the season of higher water temperature, while the typical form of crassa represents the form appearing in the season of lower water temperature. Especially the latter author noted this more in detail, mentioning that the individuals once experienced lower temperatures below $7^{\circ} \mathrm{C}$ in their development will produce a thicker collarette. Further, he tried the indoor and outdoor rearing of $\mathrm{f}$. naikaiensis and the typical form at the laboratory, but seemingly this did not present any definitive evidences to prove the abovementioned trend.

The mass centre of $f$. naikaiensis is found in the warmer season usually in the inlets or coves of the Inland Sea, while the occurrences of the typical form of crassa in the colder season are usually found in the open area of the sea, and there the typical form is accompanied with such plankton animals as Flaccisagitta enflata, Okiopleura longicauda, Lucifer and a few oceanic copepods including Calanus helgolandicus and some species of Eucalanus (Kado, 1953 and 1973). Some of f. naikaiensis can be seen in the winter season, too. Thus, it has been suspected that the typical form of crassa and $f$. naikaiensis might not be the forms representing the different generations of the same population, the former being possibly transported there by the wind prevailingly

1) Contributions from the Seto Marine Biological Laboratory, No. 587.

Publ. Seto Mar. Biol. Lab., XXI (3/4), 269-279, 1974.

(Article 18) 
blowing from the northwest in winter months. If this is true, f. naikaiensis might be better treated as a variety or a subspecies of crassa.

Aidanosagitta crassa f. tumida (Tokioka) was first described, from the Lake Notoro on the Okhotsk coast of Hokkaido Island, Japan, as a distinct species. Later, however, it was included in crassa as only a form of this species (Tokioka and Pathansali 1963, Tokioka 1965), though no explanation has been made as to this treatment. Evidently, this accords to the treatment of $\mathrm{f}$. naikaiensis of Aidanosag. crassa. If it is admitted that naikaiensis is nothing more than a form of Aidanosag. crassa, then the remarkable difference in the appearance of collarette should be insignificant as a specific criterion. Other features, else than the collarette appearance, and the armature formula of tumida, a small inlet-water species, show no essential differences from those of crassa and its form naikaiensis. The armature formula of tumida might seemingly be regarded as continuous to that of smaller individuals of naikaiensis, the mature specimens of naikaiensis then show the formula just similar to that of the typical form of crassa in the same range of body length. The decrease in body size in tumida may be explained as in the cases of smaller Parasagitta elegans in the Lake Ogac (Dunbar, 1962) and a small form of Zonosagitta bedoti in the littoral waters near Penang, Malaya (Tokioka and Pathansali, 1965). The isolated occurrence of tumida will be referred to in a future paper.

Recently, a number of new species have been defined on minor morphological characteristics, though this has been done mostly in correlation with the segregation of water masses in which they live. On the other hand, some forms with markedly different features are united under the single same species as mentioned above. Thus, it has been urged to see exactly whether or not the differences between the typical form of Aidanosag. crassa, f. naikaiensis and tumida are truly of an intraspecific nature.

The Lake Notoro is a small, nearly round lake, of about $59 \mathrm{~km}^{2}$ and about $20 \mathrm{~m}$ deep at the maximum. It is completely separated by a narrow dune from the Okhotsk Sea, but in the period from May to August a small artificial canal is cut through the dune to maintain the communication between the lake and the sea in a small scale, though this is seemingly enough to allow the sea and lake fishes to come in and go out. In the end of the summer season, the canal will be closed by the drifting sand of the shore and this state will continue to the next spring when the dune is cut through again.

As tumida was described on immature specimens, it had been one of my earnest desires to make some plankton collection in the Lake Notoro to obtain mature tumida. Thus, I visited the lake in August 1963 and made several vertical hauls of a plankton net on August 27, when the canal had been closed already. The water body of the lake below $10 \mathrm{~m}$ was thoroughly occupied by densely blooming dinoflagellates, Ceratium fusus, and the animal plankters were found limitedly in the surface stratum above $10 \mathrm{~m}$. A number of very small chaetognaths were found in all samples. And unexpectedly, they were not tumida, but all were miniatures of f. naikaiensis of Aidanosag. 
crassa. At this, it was supposed immediately that tumida must doubtlessly be a form of crassa and that individuals with features of tumida would appear next spring in the lake. The second collection of plankton samples was made on May 9, 1964 just after the dune had been cut through. That time, blooming Ceratium fusus occupied the surface layer of the lake water above $10 \mathrm{~m}$ and the animal plankters were limited in the bottom stratum below $10 \mathrm{~m}$. As expected, all chaetognaths were of the typical tumida-type, but unfortunately no mature individuals were included. The winter

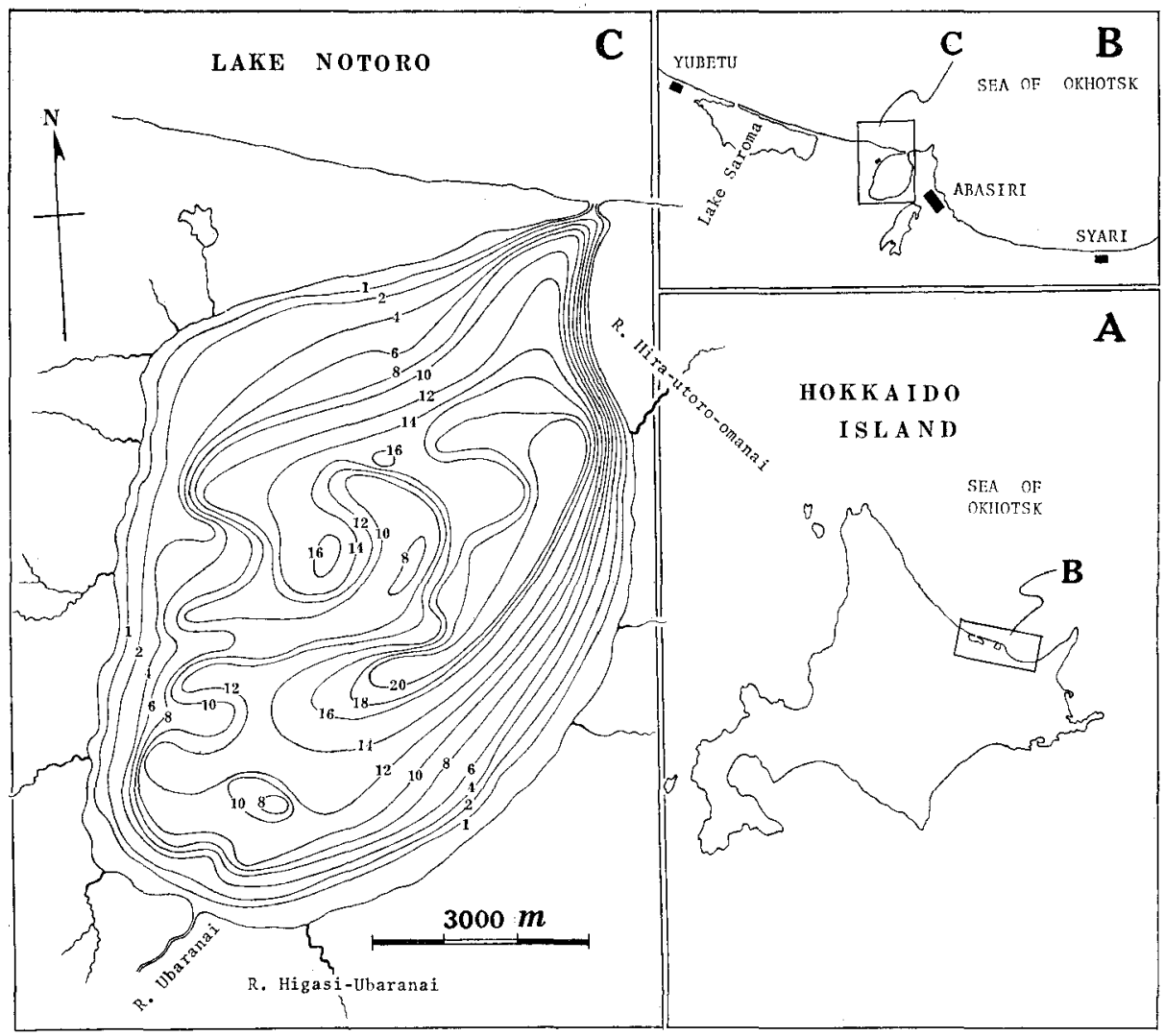

Fig. 1. Maps showing the Lake Notoro and its situation in Hokkaido Island.

1964-65 was noted by so heavy snow in Hokkaido. In spring 1965, the fields around the lake were flooded by the lake water raised to an unusual level by thawing. It was urged to cut through the dune as early as possible, and when this was done, the outflow of the lake water enlarged the canal unexpectedly. The lake and the sea had a wide connection that year. The third collection was made on June 24, 1965, but no chaetognath was found in any plankton samples; the water was very clear and contained no cells of Ceratium fusus. After that, I have had no chance to make collection 
at the lake by myself. Some collections made by some others included immature individuals of the tumida-type, but so far no mature individuals have been reported.

Nevertheless, it is now confirmed that remarkable morphological differences are found between the generations of evidently the same chaetognath population, and this will not only explain definitely the interrelation between Aidanosag. crassa and its $f$. naikaiensis, but also seemingly suggest some probable interpretation as to the significance of minor morphological differences and further their specific validity in some chaetognaths living in the neritic waters or in the mixing region between the water masses of different natures.

\section{Morphology of the Lake Chaetognaths Having Developed in the Warm Water Season (Summer Specimens)}

The material included $960 \mu$ to $5.2 \mathrm{~mm}$ long individuals. The mature specimens in the Stages III and IV of the ovarian development are 4.2 to $5.1 \mathrm{~mm}$ in body length. The tail segment in mature individuals is about $30 \%$ of the total body length inclusive of the caudal fin. The general appearance of the body resembles closely that of smaller individuals of $f$. naikaiensis of Aidanosag. crassa. The body is slender, with the narrow anterior fin beginning short behine the posterior end of the ventral ganglion (the distance to the ganglion is less than a half of the ganglion length) and shorter than the posterior fin which is widest behind the trunk-tail septum. The caudal fin is triangular. No rayless-zone is seen in any fins in a perfect state; rays are easily obscured by abrasion. The collarette is found in the neck region within the range of about the head length, but it is quite insignificant (Fig. 3a). The corona ciliata is lost by abrasion. Hooks are generally 7 to 8 , the anterior teeth $2-3$ and the posterior teeth $4-6$, mostly 5 in mature individuals.

Table 1. Armature of the summer specimens.

\begin{tabular}{ccccc}
\hline $\begin{array}{c}\text { Body length } \\
\text { mm }\end{array}$ & $\begin{array}{c}\text { Tail segment } \\
\text { in \% }\end{array}$ & Hooks & $\begin{array}{c}\text { Anterior } \\
\text { teeth }\end{array}$ & $\begin{array}{c}\text { Posterior } \\
\text { teeth }\end{array}$ \\
\hline 3.8 & 39.1 & $8-8$ & $2-2$ & $3-4$ \\
4.0 & 31.4 & $8-8$ & 2 & 3 \\
4.0 & 34.5 & $8-8$ & $2-2$ & $4-4$ \\
4.4 & 29.0 & $7+1-8$ & $2-3$ & $4-5$ \\
4.5 & 33.3 & $7-8$ & $3-3$ & $5-5$ \\
4.6 & 30.9 & $8-8$ & $3-3$ & $5-5$ \\
4.6 & 31.5 & $7-7$ & $3-3$ & $5-5$ \\
4.6 & 29.6 & $7-8$ & $2-3$ & $4-5$ \\
4.7 & 29.7 & $8-8+1$ & $3-3$ & $4-5$ \\
4.8 & 29.2 & $7-7$ & $2-3$ & $5-5$ \\
5.1 & 28.5 & $7-7$ & $3-3$ & $5-6$ \\
\hline
\end{tabular}




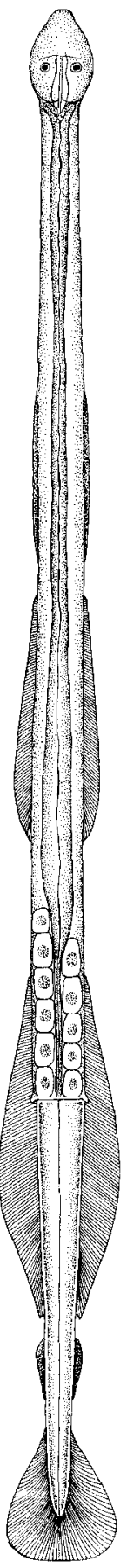

Fig. 2


Fig. 3

Fig. 2 (left), Aidanosagitta crassa f. tumida (Tokioka), a summer specimen developed in the warm season, dorsal, $\times 35$.

Fig. 3 (above). Aidanosagitta crassa f. tumida (Tokioka), summer specimens, $\times 75$. a-anterior part of body, dorsal. b-fully matured seminal vesicles. $\mathrm{c}$ - -seminal vesicles in Stage II. d-vesicle, ruptured. 
The outline of eye-pigments is rather large and roundish. The intestinal diverticula are very distinct as seen in Fig. 3a. The ovary appears in $3.0 \mathrm{~mm}$ long individuals in the Stage I and develops to the Stage II at about $3.5 \mathrm{~mm}$ and further to the Stages III and IV in the range of 4.2-4.5 $\mathrm{mm}$. Up to 5-6 mature eggs are found in each ovary, the anterior end of which may extend far beyond the anterior end of the posterior fin, but never reaches the posterior end of the anterior fin. The seminal vesicle is situated nearer to the posterior fin than to the caudal fin. This situation can be confirmed clearly in perfectly preserved specimens with mature vesicles. The posterior end of the posterior fin is very easily torn and this makes it difficult to see the exact situation of the vesicle. Especially in younger specimens, in which even the rudimentary vesicles have not yet been definable, the epidermis is rather thickened more prominently in the posterior half of the distance between the posterior and caudal fins, and this might lead one to an incorrect supposition that the vesicle would be situated at just the base of the caudal fin. The thickening to the vesicle (Stage I) starts in $3.3 \mathrm{~mm}$ long individuals, this develops to the Stage II at around $3.7 \mathrm{~mm}$ and further to the Stages III and IV in individuals over $4.0 \mathrm{~mm}$.

\section{Morphology of the Lake Chaetognaths Having Developed in the Cold Water Season (Winter Specimens)}

The material included 2.8 to $4.7 \mathrm{~mm}$ long specimens. These winter specimens are constructed quite the same as the individuals described in 1939 (Fig. 4). The tail segment is 31 to $33 \%$ of the body length inclusive of the caudal fin in larger specimens. Hooks are 8-9, the anterior teeth $1-3$ and mostly 2, and the posterior teeth up to $4-5$.

Table 2. Armature of the winter specimens.

\begin{tabular}{cclcc}
\hline \hline $\begin{array}{c}\text { Body length } \\
\text { mm }\end{array}$ & $\begin{array}{c}\text { Tail segment } \\
\text { in \% }\end{array}$ & Hooks & $\begin{array}{c}\text { Anterior } \\
\text { teeth }\end{array}$ & $\begin{array}{c}\text { Posterior } \\
\text { teeth }\end{array}$ \\
\hline 3.7 & 32.0 & $8-8$ & $2-2$ & $4-5$ \\
3.7 & 35.4 & $9-9+1$ & $2-2$ & $3-3$ \\
3.9 & 31.1 & $8-8$ & $1-2$ & $2-2$ \\
3.9 & 33.3 & $9-9$ & $2-2$ & $3-3$ \\
4.2 & 31.1 & $8-9$ & $2-2$ & 5 \\
4.2 & 33.8 & $8-8+1$ & 3 & 4 \\
4.3 & 32.2 & $8-8+1$ & $2-2$ & $4-4$ \\
4.4 & 33.3 & $8-8$ & $2-2$ & $4-5$ \\
4.4 & 32.5 & $9-9$ & $2-2$ & $4-5$ \\
4.7 & 31.5 & $8-8$ & $1-1$ & $2-2$ \\
4.7 & 33.3 & $8-9$ & $2-2$ & $4-4$ \\
\hline
\end{tabular}




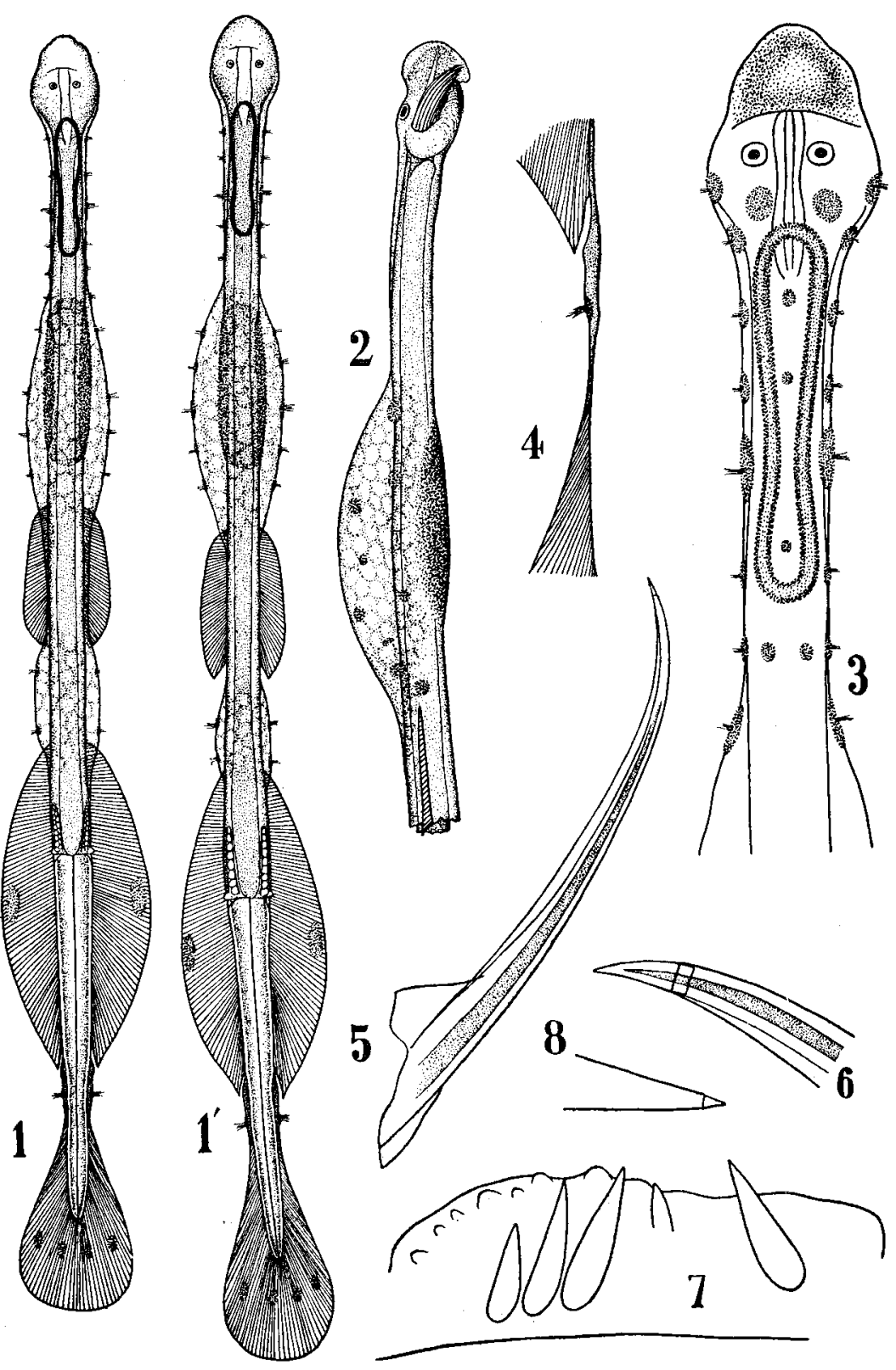

Fig. 4. Aidanosagitta crassa f. tumida (Tokioka), winter specimens developed in the cold season (after Tokioka, 1939b).

1, 1'-entire animals, dorsal, $\times 35$. 2-anterior portion of $1^{\prime}$, lateral, $\times 45$. 3-anterior part of body, dorsal, $\times 90$. 4-posterior part of tail segment, $\times 90$. 5-hook, $\times 550$. 6 -tip of hook, $\times 1500$. 7-left anterior and posterior teeth, $\times 900$. 8-tip of anterior tooth, $\times 1500$. 
The seminal vesicles are not yet definable in any specimens. The ovary in the Stage I appears in $3.4 \mathrm{~mm}$ long individuals, while the Stage II is observed in individuals larger than $3.7 \mathrm{~mm}$. No further stages are defined in the material. Although the specimens are more or less abrased, the formation of the typical collarette is found in a $3.2 \mathrm{~mm}$ long specimen. Probably all the specimens in the material would have been furnished with the well developed collarette, if the abrasion had not occurred in hauling the net.

\section{Considerations}

Marked morphological differences are clearly recognized between the summer and winter specimens of the same chaetognath population in the Lake Notoro, but it is not yet known whether the morphological changes take place gradually or abruptly, as the number of generations repeated in respective seasons is still unknown ${ }^{2)}$; naturally generations in the winter season must be very much limited. Anyhow, the above-mentioned morphological differences evidently must be reflecting the remarkable environmental differences between the two seasons: the low water temperature in winter, with a little decline of salinity in spring, and the high water temperature in summer, with a slight enhancement of salinity.

Table 3. Some records of the water temperature and salinity in the Lake Notoro.

\begin{tabular}{|c|c|c|}
\hline Date & Water temperature in $\mathbf{C}$. & Salinity $\%$ \\
\hline March 7, 1938 & $-1.3-0.5$ & $24.88-25.07$ \\
\hline May 9,1964 & $10-11.1$ (surface) & \\
\hline June $11-14,1932$ & (bottom) $8.7-23.8$ (surface) & $27.48-30.90$ \\
\hline June 24, 1965 & 13.8 (at $10 \mathrm{~m}$ ) & \\
\hline October $30-31,1932$ & (surface) 11.5-14.6 (lower layer) & $26.18-31.58$ \\
\hline
\end{tabular}

The morphological differences between the individuals of the two seasons may be summarized as follows:

\begin{tabular}{lcc}
\hline \hline & Summer specimens & Winter specimens \\
\hline $\begin{array}{c}\text { Body length of } \\
\text { mature individuals }\end{array}$ & up to $5.2 \mathrm{~mm}$ & $\begin{array}{c}\text { unknown, but probably } \\
\text { not so much larger than } \\
\text { the summer specimens. }\end{array}$ \\
$\begin{array}{l}\text { Tail segment } \\
\text { Collarette }\end{array}$ & $30 \%$ & $31-33 \%$ \\
& insignificant & $\begin{array}{c}\text { markedly and strangely } \\
\text { formed }\end{array}$ \\
\hline
\end{tabular}

2) The individuals are seemingly still in the end of October in the form of summer specimens as they were noted as Sagitta sp. (Hokkaido Fisheries Experimental Station, 1934, p. 74), while those found in the middle of June and probably in the'form of winter specimens were identified with Sagitta regularis (1.c., pp. 68 and 72 ). 


$\begin{array}{lcc}\text { Anterior fin } & \begin{array}{c}\text { slightly longer } \\ \text { triangular }\end{array} & \begin{array}{c}\text { slightly shorter } \\ \text { rather spatulate }\end{array} \\ \text { Caudal fin } & 7-8 & 8-9 \\ \text { Hooks } & 2-3 & 2(1-3) \\ \text { Anterior teeth } & 5(4-6) & 4-5\end{array}$

The difference in length of the anterior fin should be correlated with the development of the collarette, or the anterior fin generally appears later than the posterior fin in chaetognath development and then the shorter fin might represent a comparatively earlier developmental stage of the fin. The spatulate caudal fin is apparently of a juvenile feature. The number of hooks generally decreases in many species with age after a certain developmental stage, although it is related with age in some limited number of species. Thus, the existence of a little more hooks in the winter specimens may be accepted in the present case as a sign of an earlier developmental stage than the state of the summer specimens. On the contrary, the anterior and posterior teeth usually increase with age, though exceptionally decrease in aged specimens in a few species. And thus, the armature of the winter specimens with slightly fewer teeth than in the summer specimens seems also to indicate a relatively earlier stage of the growth. The existence of a little more teeth in the individuals developed in the summer season as compared with those developed in the winter season (and probably slightly less hooks in the former than in the latter) is noted already by Kado (1954) in Aidanosag. crassa as seen in Table 4. The tail segment seems slightly larger in the winter specimens, but such a slight difference might be insignificant. If the difference is significants, this must be one of the juvenile features, too.

Table 4. Armature of 56 mm individuals of Aidanosag. crassa (After Kado, 1954).

\begin{tabular}{lccc}
\hline \hline & Hooks & $\begin{array}{c}\text { Anterior } \\
\text { teeth }\end{array}$ & $\begin{array}{c}\text { Posterior } \\
\text { teeth }\end{array}$ \\
\hline $\begin{array}{c}\text { Individuals in } \\
\text { January to June } \\
\text { Individuals in } \\
\text { July to December }\end{array}$ & $8-9$ & $3-5$ & $6-9$ \\
\hline
\end{tabular}

Throughout the features of the winter specimens, exclusive of the appearance of the collarette, it may safely be concluded that the winter specimens are more conservative in maintaining juvenile features as compared with the summer specimens. The observed largest winter specimen was $4.7 \mathrm{~mm}$ in body length and the ovary in the individuals of such a body length was in the Stage II defined by Thomson. Taking the growth of the summer specimens in the period from the Stage II to the last IV of the ovarian maturation in consideration, it may be conjectured that the fully mature winter specimens might be about $5.7 \mathrm{~mm}$ in body length. This is a little larger than 
in the summer specimens ( $5.2 \mathrm{~mm}$ long at the maximum), but the increase in size of mature individuals in the colder waters is an evident trend seen generally in a number of animals.

This phenomenon showing a distinct morphological change between the generations of the same chaetognath population in correlation with the regular alternation of the hydrographic conditions in the same water body offers a very important suggestion as to the taxonomy of the chaetognaths which are rather eurythermal and euryhaline and thus are living in the neritic waters or in the intermixing areas between different water masses, where the temperature and salinity will change markedly from place to place and from time to time. In the neritic waters, the open area and inlet generally differ constantly from each other in hydrographic conditions. However, there must be some interchange of the water between the inlets and adjacent open areas, and accordingly some part of the population of an inlet chaetognath may develop the next generation outside the inlet. And the individuals of that generation developed in the open area, of somewhat different hydrographic conditions, outside the inlet may assume some characteristic morphology which differs distinctly from that of individuals of the forerunning generation in the inlet. Further, this difference will be retained between the individuals in and outside the inlet, as far as the hydrographic conditions in respective habitats are maintained rather constantly as seen in lower latitudes. This mechanism might be applied to the case of Sagitta tenuis Conant (inlet) and Sagitta friderici Ritter-Zahony (open-area). Further, in more or less modified ways, it may be applicable to the case of Aidanosag. crassa (Tokioka) and its f. naikaiensis and further to that of Zonosagitta bedoti (Béraneck) and its forms. It might be possibly true as to the interrelation between Aidanosag. neglecta (Aida) and Aidanosag. oceania (Gray); in this case, however, the differentiation might be definitive as the former is clearly an oceanic form. The same principle may be applicable to an eurythermal pure oceanic species Flaccisagitta lyra (Krohn) in the mixing region between the warm (Kurosio) and cold (Oyasio) currents (and probably also between the oceanic water and the neritic water along the continent) in the northern North Pacific. Flaccisag. scrippsae (Alvariño) might be only the form of individuals of lyra, belonging to the generation developed in a little colder water north of the narrow mixing water flowing east approximately along $40^{\circ} \mathrm{N}$ (Kito, 1966). If such interpretations are accepted, then it will naturally be requested that the systematic treatment is changed in some pairs or groups of closely allied forms, apart from the significance of admitting clear morphological differences in the same species, in correlation with the hydrographic conditions; such differences must be very effectual in defining water masses of exact hydrographic natures. 


\section{REFERENCES}

Dunbar, M.J. 1962. The life cycle of Sagitta elegans in Arctic and Subarctic seas, and the modifying effects of hydrographic differences in the environment. Jour. Mar. Res., 20(1), 76-91.

Hokkaido Fisheries Experimental Station 1934. Limnological surveys of Yudo-numa, Onne-to, and Notoro-ko. Reports on Fisheries Surveys, no. 36, 49-83 for the Lake Notoro.

Kado, Y. 1953. The chaetognath fauna of the Inland Sea of Japan, especially on the distribution of Sagitta enflata and S. crassa. Zool. Mag. Tokyo, 62(10), 337-342; in Japanese, with English summary. 2 tables.

1973. Sagitta enflata and Sagitta crassa in the Inland Sea of Japan. Ocean Research Institute (Tokyo University) Symposium on Chaetognatha, 1973. Lecture II-8.

Kito, M. 1966. Distribution de Chaetognatha dans l'abysse du Pacifique du Nord. Bull. Soc. francojapon. Océanogr., 4(1), 78-86.

Murakami, A. 1959. Marine biological study on the planktonic chaetognaths in the Seto Inland Sea. Naikai Reg. Fish. Res. Lab., Report no. 12, 186 pp; in Japanese, with English summary.

Tokioka, T. 1939a. Three new chaetognaths from Japanese waters. Mem. Imp. Mar. Observatory, $7(1), 129-140$.

1939b. A new brackish-water chaetognath. Annot. Zool. Japon., 18(4), 277-280, pl. 14.

1959. Observations on the taxonomy and distribution of chaetognaths of the North Pacific. Publ. Seto Mar. Biol. Lab., 7(3), 349-456, 9 tables.

1961. Notes on Sagitta friderici Ritter-Záhony collected off Peru. Postilla, 55, 16 pp.

1965. The taxonomical outline of Chaetognatha. Publ. Seto Mar. Biol. Lab., 12(5), 335-357.

Tokioka, T. and D. Pathansali 1963. Another new chaetognath from Malay waters, with a proposal of grouping some species of Sagitta into subgenera. Publ. Seto Mar. Biol. Lab., 11(1), 119-123, pl. 7 .

and

1965. A new form of Sagitta bedoti Béraneck found in the littoral water near Penang. Bull. National Mus. Singapore, 33(1), 5 pp. 